\title{
Electrodeposited Reduced Graphene Oxide Films on Stainless Steel, Copper, and Aluminum for Corrosion Protection Enhancement
}

\author{
Abdulkareem Mohammed Ali Al-Sammarraie and Mazin Hasan Raheema \\ Department of Chemistry, College of Science, University of Baghdad, Baghdad, Iraq \\ Correspondence should be addressed to Abdulkareem Mohammed Ali Al-Sammarraie; samuraee2000@hotmail.com
}

Received 23 November 2016; Revised 8 February 2017; Accepted 16 February 2017; Published 2 April 2017

Academic Editor: Ramazan Solmaz

Copyright (C) 2017 Abdulkareem Mohammed Ali Al-Sammarraie and Mazin Hasan Raheema. This is an open access article distributed under the Creative Commons Attribution License, which permits unrestricted use, distribution, and reproduction in any medium, provided the original work is properly cited.

\begin{abstract}
The enhancement of corrosion protection of metals and alloys by coating with simple, low cost, and highly adhered layer is still a main goal of many workers. In this research graphite flakes converted into graphene oxide using modified Hammers method and then reduced graphene oxide was electrodeposited on stainless steel 316, copper, and aluminum for corrosion protection application in seawater at four temperatures, namely, 20, 30, 40, and $50^{\circ} \mathrm{C}$. All corrosion measurements, kinetics, and thermodynamics parameters were established from Tafel plots using three-electrode potentiostat. The deposited films were examined by FTIR, Raman, XRD, SEM, and AFM techniques; they revealed high percentages of conversion to the few layers of graphene with confirmed defects.
\end{abstract}

\section{Introduction}

Graphene has attracted extreme interest in the industrial and scientific community since the experimental realization of graphene in 2004 [1], for many reasons; graphene has the highest electronic conductivity at room temperature; and it is only one monoatomic layer thick and almost transparent; it is durable and at the same time flexible; it is chemically inert and impermeable to most gasses. The chemical inertness and impermeability towards most gasses in combination with its strength and single atomic layer thickness make it a fascinating candidate for coating purposes, particularly for anticorrosion coatings; a new and better protecting material has been sought intensively [2, 3]. Graphene as nanosheets and nanoplatelets and functionalized graphene can be prepared by various methods such as chemical vapor deposition, chemical or mechanical exfoliation, and cleavage and annealing a single-crystal $\mathrm{SiC}$ [4-8]. Most of these methods need high energy requirement with low production yield. Among the preparation methods, chemical process has become a promising route to produce graphene sheets; it is simple, inexpensive, and suitable for large-scale or mass production. The process involves significant steps: graphite oxidation, exfoliation of graphite oxide, and reduction of graphene oxide sheets [9].

Graphene-polymers composites based materials have found wide applications in corrosion protective coatings applications [10-14], and little work has been done to aid in the corrosion protection of metal and alloys using graphene layer alone due to weak adhesively on metal surfaces. This study focused on the chemical synthesis and deposit of well-adhered graphene coating to shield carbon steel for enhancing the corrosion protection. The effectiveness of the graphene-metal coating is estimated via electrochemical procedure in $3.5 \mathrm{wt} \% \mathrm{NaCl}$ aqueous solution. The test serves to deduce the corrosion inhibition ability of the graphene.

\section{Materials and Methods}

All chemicals and materials used in this work were used as received.

2.1. Preparation of Graphene Oxide. Graphene oxide was synthesized from graphite flakes by Hummers Jr. and Offeman method [15], graphite (1.0 g) (Mesh100, Sigma-Aldrich, USA) 
was added to $23 \mathrm{~mL}$ of concentrated sulphuric acid (BDH, "AnalaR" sp. gr. 1.84) under stirring at room temperature, then $0.5 \mathrm{~g}$ of sodium nitrate (BDH, "AnalaR") was added, and the mixture was cooled to $0^{\circ} \mathrm{C}$. Under powerful agitation, $3.0 \mathrm{~g}$ of potassium permanganate (BDH, GPR) was added slowly while the temperature of the suspension was kept near $2^{\circ} \mathrm{C}$. The reaction mixture was transferred to a water bath at a temperature of $35^{\circ} \mathrm{C}$ and stirred for $30 \mathrm{~min}$. Then, $50 \mathrm{~mL}$ of deionized water DI $(\sim 1 \mu \mathrm{s} \cdot \mathrm{cm})$ was added, and the solution was stirred for $15 \mathrm{~min}$ at $90^{\circ} \mathrm{C}$. Additional $166 \mathrm{~mL}$ of water was added and followed by a slow addition of $5 \mathrm{~mL}$ of hydrogen peroxide (30\%, Seema International), turning the color of the solution from yellow to dark brown. The mixture was filtered and rinsed with $85 \mathrm{~mL}$ of $4 \% \mathrm{HCl}$ aqueous solution followed by washing with $65 \mathrm{~mL}$ of distilled water to remove the acid, and then oxidation product was washed until the $\mathrm{pH}$ reached 6 and then filtered, dried, and examined by FTIR, Raman, AFM, and SEM techniques.

2.2. Deposition of Reduced Graphene Oxide. Suspension of the produced graphene, as described in step 1, was prepared by adding $0.5 \mathrm{~g}$ of graphene oxide powder to $100 \mathrm{~mL}$ of distilled water; an ultrasonic probe homogenizer (MTI, USA, $300 \mathrm{~W}$ ) was used to mix the solution for $10 \mathrm{~min}$. The GO solution was transferred into two-electrode glass cell body $(25 \mathrm{~mL})$, and a well cleaned and polished piece of the metal under investigation (SS316, Cu, and $\mathrm{Al}$ ) serves as cathode, while a piece of pure platinum acts as anode, and the two electrodes were connected to a DC power supply. The deposition starts on applying several DC volts for several minutes. Each metal deposited at ranges of potentials and times and the layers were visually examined

It seemed that a mixed function of the electroreduction process, first reduction of the graphene oxide, and the second one is electrophoretic deposition (EPD) of the graphene layers on the metal surfaces. The adherence power was tested with simple plaster tape procedure according to ASTM D82395(2012) el.

The deposited graphene layers were characterized using XRD, FTIR, Raman, AFM, and SEM.

2.3. Corrosion Measurement. The corrosion tests were conducted with the use of advanced potentiostat (Wenking MLab-200, Bank Elektronik-Intelligent Controls $\mathrm{GmbH}$, Germany) with all accessories, cell, electrode, and working electrode holder. The corrosive medium was artificial sea water made by dissolving $35 \mathrm{~g}$ of $\mathrm{NaCl}$ in 1-liter distilled water, the polarization curves were scanned between -200 and $+200 \mathrm{mv}$ from the open circuit potential and the corrosion currents $i_{\text {corr }}$, and corrosion potentials $E_{\text {corr }}$ were evaluated by extrapolation of the cathodic and anodic Tafel lines from the polarization curves at four different temperatures, namely, 20, 30,40 , and $50^{\circ} \mathrm{C}$.

\section{Results and Discussion}

3.1. Graphene Oxide Characterization. The FTIR spectrum of the produced graphene oxide, GO (brown in color),

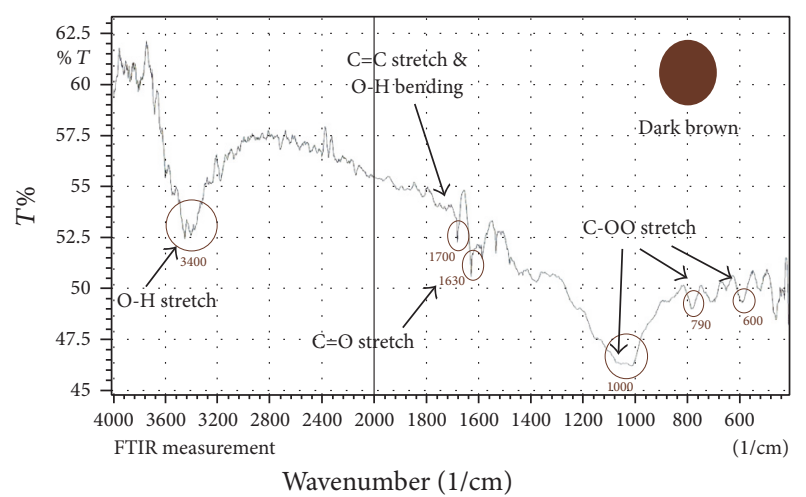

FIGURE 1: The FTIR transmission spectrum of GO produced by Hammers method.

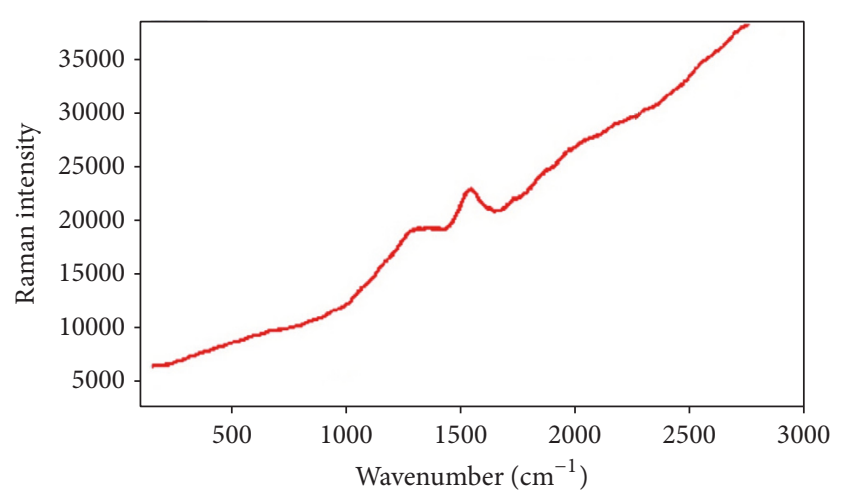

FIgURE 2: Raman spectrum of the graphene oxide sheets produced by modified Hammers method from graphite flakes.

showed transmission peaks at 3400, 1700, 1630, 1400, and $1080 \mathrm{~cm}^{-1}$, belonging to the stretching and bending of the vibrations of the $\mathrm{O}-\mathrm{H}$ and $\mathrm{C}=\mathrm{O}$ from carbonyl groups, $\mathrm{C}=\mathrm{C}$ configurable vibrations from the aromatics, and $\mathrm{C}-\mathrm{OO}$ stretching vibrations [16], as assigned in Figure 1.

Figure 2 shows the Raman spectrum of the produced graphene oxide characterized by the appearance of broad peak at wavelength at $1355 \mathrm{~cm}^{-1}$, which belonged to the band $\mathrm{D}$, with the peak of band $\mathrm{G}$ which belonged to graphite [17].

The SEM images in Figure 3 show the morphology and topographic structure of the produced GO; they represent nanoplates with thicknesses varying between 15 and $65 \mathrm{~nm}$.

Similar estimation of the GO nanoplates thicknesses was deduced from section line AFM analysis as shown in Figure 4.

Figure 5 shows the XRD spectrum for the started graphite flakes and the produced GO which proved the success of the conducted chemical exfoliation process; the main peaks at $2 \theta$ of $26.5^{\circ}$ belonging to the plane (200) [18] became broader which means much less numbers of graphene layers as estimated using Scherer equation [19].

3.2. Electrodeposited Reduced GO Characterization. The FTIR spectrum of the reduced GO revealed the absence of the $\mathrm{C}-\mathrm{O}$ and $\mathrm{C}-\mathrm{OH}$ absorption bands; the only peaks belonged to $\mathrm{C}=\mathrm{C}$ and $\mathrm{C}-\mathrm{H}$ vibrations bands, as shown in Figure 6 . 

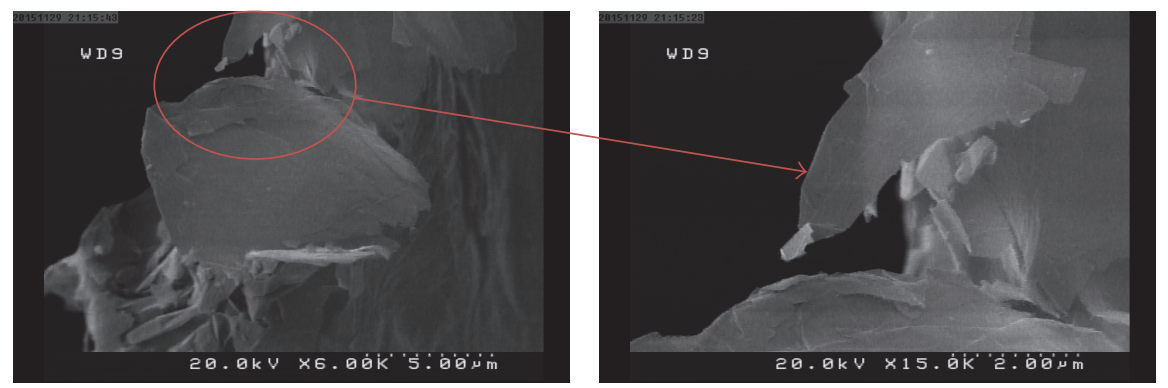

FIGURE 3: SEM images of graphene oxide sheets produced by modified Hammers method from graphite flakes.
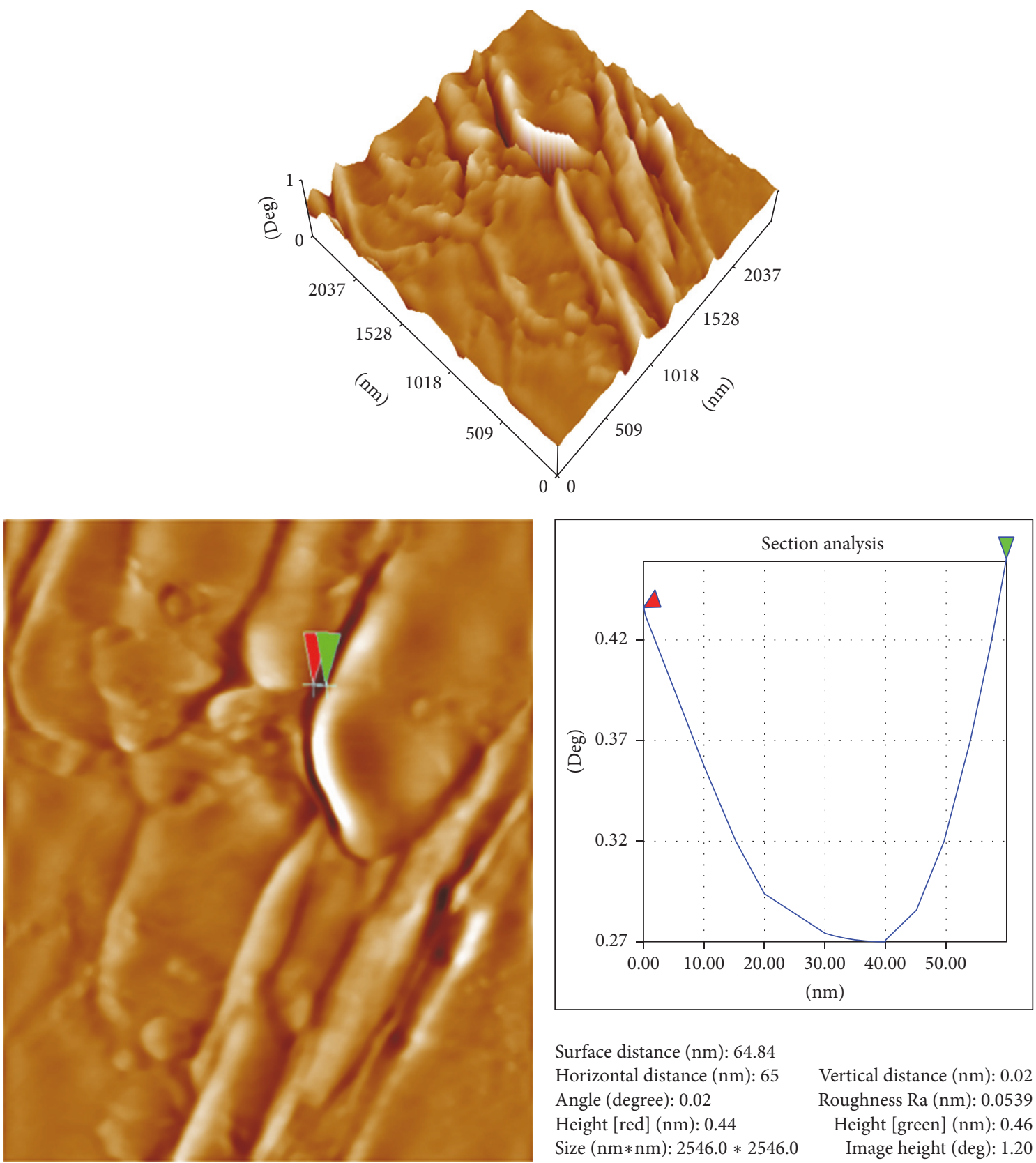

Surface distance (nm): 64.84

Horizontal distance (nm): 65

Angle (degree): 0.02

Height [red] (nm): 0.44

Size $(\mathrm{nm} * \mathrm{~nm}): 2546.0 * 2546.0$

Vertical distance (nm): 0.02 Roughness Ra (nm): 0.0539 Height [green] (nm): 0.46 Image height (deg): 1.20

FIGURE 4: AFM images show the 3D and section line analysis of GO produced by modified Hammers method from graphite flakes. 


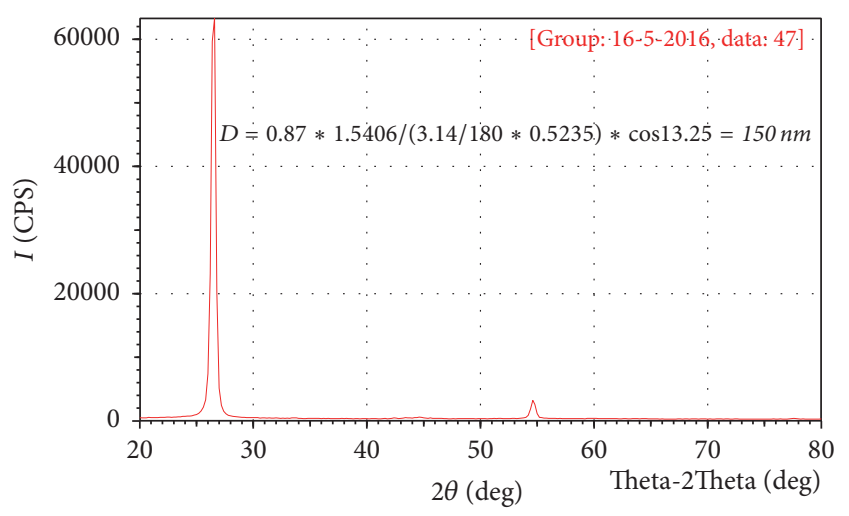

(a)

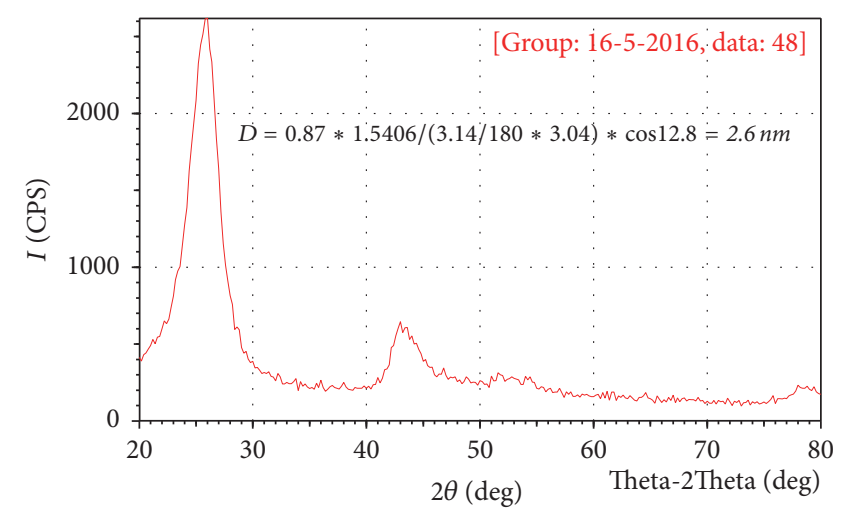

(b)

FIGURE 5: The XRD spectrums for the started graphite flakes (a) and the produced GO (b).

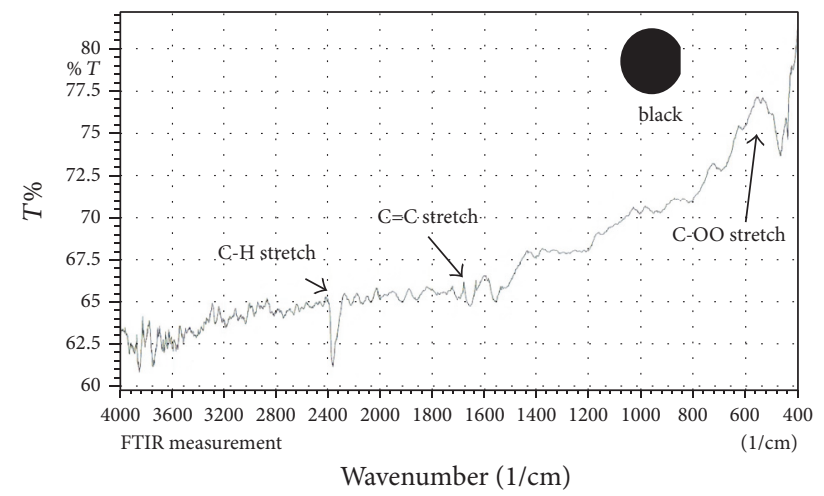

FIGURE 6: The FTIR transmission spectrum of electroreduced GO produced by Hammers method.

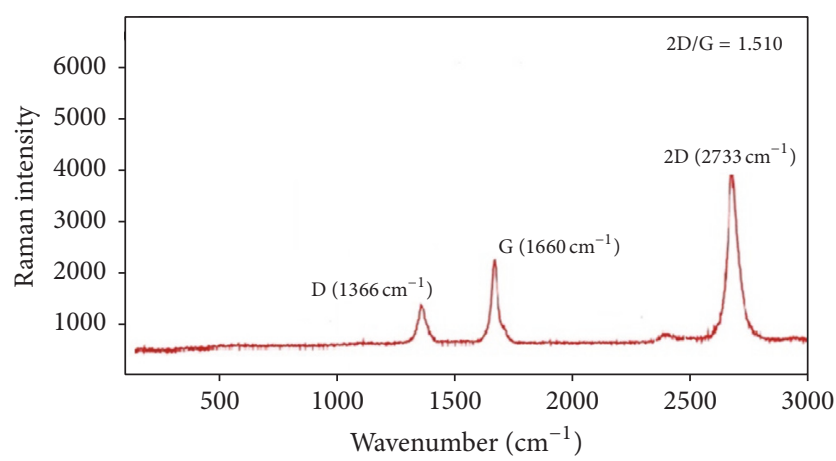

FigURE 7: Raman spectrum of the electroreduced GO produced by Hammers method.

Figure 7 shows the Raman spectrum of the reduced graphene oxide; it recorded the appearance of the peak $2733 \mathrm{~cm}^{-1}$ which belongs to the $2 \mathrm{D}$ band, in addition to the peaks (1366 and $1660 \mathrm{~cm}^{-1}$ ) for D band and $\mathrm{G}$ band, respectively, indicating that the produced graphene sheets got some degree of defection; the $2 \mathrm{D} / \mathrm{G}$ intensity ratio was 1.51 which means that the reduced GO was composed of multiple layers of defected graphene nanosheets [20].
The SEM images for the reduced graphene oxide in Figure 8 revealed larger areas of nanosheets with smaller thicknesses which attributed to the loss of the oxygen bonds (carbonyl, epoxides, etc.) due to the reduction process [9, 21].

The cross-sectional analysis of the AFM scans shows a thicknesses $(\sim 15 \mathrm{~nm})$ smaller than that of the GO before electroreduction step, as shown in Figure 9.

3.3. Corrosion Parameters Measurement. Figures 10, 11 , and 12 show Tafel polarization curves of the uncoated and reduced graphene oxide coated SS316, copper, and aluminum in seawater, respectively, in the temperature range $\left(20-50^{\circ} \mathrm{C}\right)$.

The corrosion potentials $\left(E_{\text {corr }}\right)$ in $\mathrm{mV}$ versus SCE, the corrosion current density $\left(i_{\text {corr }}\right.$ in $\left.\mu \mathrm{A} \cdot \mathrm{cm}^{-2}\right)$ and $\beta_{\mathrm{a}}$, and $\beta_{\mathrm{c}}$ in $\mathrm{mv} \cdot \mathrm{dec}^{-1}$ were established from Tafel plots (Figure 10), and weight loss (WL) in $\mathrm{g} \cdot \mathrm{m}^{-2} \cdot \mathrm{day}^{-1}$ and penetration loss in $\mathrm{mm} \cdot \mathrm{y}^{-1}$ were calculated by faradic conversions, while $\mathrm{Rp}$ in $\Omega \cdot \mathrm{cm}^{2}$ was calculated using the following equation [22]:

$$
\mathrm{Rp}=2.303\left[\frac{\beta_{\mathrm{a}} \cdot \beta_{\mathrm{c}}}{\left(\beta_{\mathrm{a}}+\beta_{\mathrm{c}}\right)}\right] * \frac{1}{i_{\text {corr }}} .
$$

Surface coverage $(\theta)$ and protection efficiencies (\% PE) were calculated from $i_{\text {corr }}$ as reported in $[22,23]$ and listed in Table 1.

The thermodynamic parameters of the corrosion process, namely, the activation energy $\left(E_{\mathrm{a}}\right)$, the entropy $\left(\Delta S^{*}\right)$, the enthalpy $\left(\Delta H^{*}\right)$, and the Gibbs free energy $\left(\Delta G^{*}\right)$ of activation, were calculated using Arrhenius plot and its derivative formulation (transition state) [24, 25]; all values are listed in Table 2.

All reduced graphene coated samples showed good enhancing for corrosion inhibition action in comparison with the bare samples; the best protection efficiencies were for SS316 and their values reached $95 \%$ at $20^{\circ} \mathrm{C}$ and then decreased with increasing temperature. While the copper and aluminum samples showed nearly constant corrosion efficiencies values (around 65\%), no effect of rising temperature was noticed in these values (Table 1).

The thermodynamic and kinetics data show that the $E_{\mathrm{a}}$ values for the graphene coated SS are higher than the 

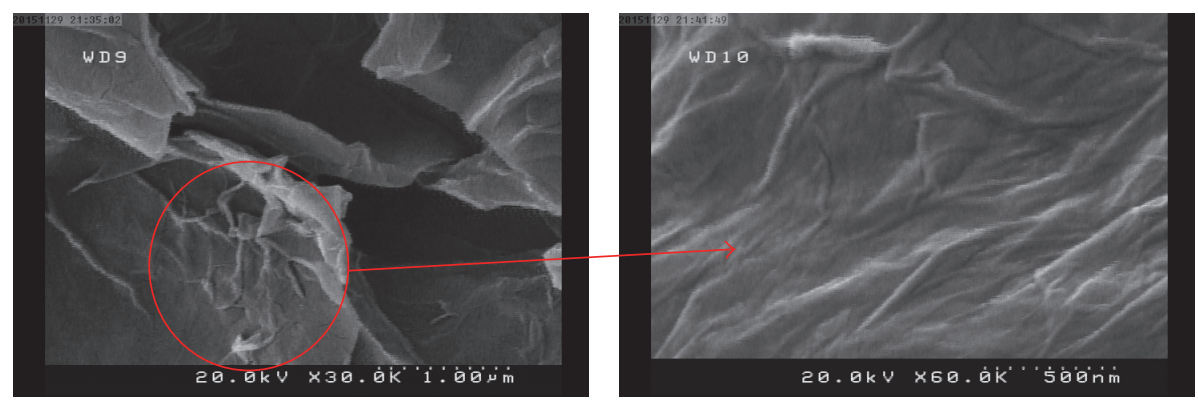

FIGURE 8: SEM images of electroreduced GO sheets produced by modified Hammers method from graphite flakes.
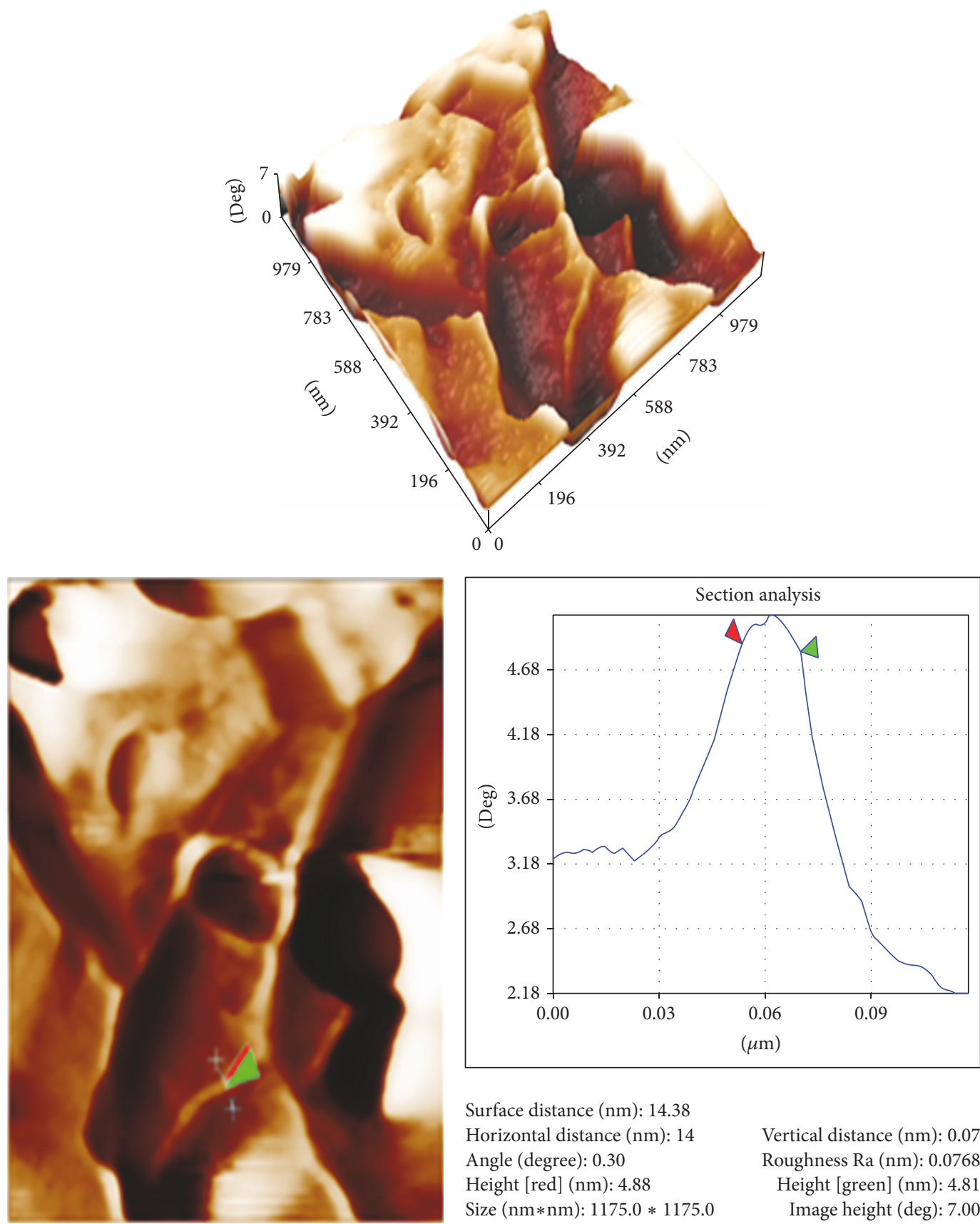

Surface distance (nm): 14.38

Horizontal distance (nm): 14

Angle (degree): 0.30

Height [red] (nm): 4.88

Size $(\mathrm{nm} * \mathrm{~nm}): 1175.0 * 1175.0$
Vertical distance (nm): 0.07 Roughness Ra (nm): 0.0768

Height [green] (nm): 4.81

Image height (deg): 7.00

FIGURE 9: AFM images show the 3D and section line analysis of electroreduced GO produced by modified Hammers method from graphite flakes. 
TABLE 1: Corrosion parameters for uncoated and graphene coated specimens in seawater at different temperature.

\begin{tabular}{|c|c|c|c|c|c|c|c|c|c|c|}
\hline Material & $T^{\circ} \mathrm{C}$ & $\begin{array}{c}E_{\text {corr }} \\
\mathrm{mV} \text { versus SCE }\end{array}$ & $\begin{array}{c}i_{\text {corr }} \\
\mathrm{mA} \cdot \mathrm{cm}^{-2}\end{array}$ & $\begin{array}{c}\beta_{\mathrm{a}} \\
\mathrm{mV} \cdot \mathrm{dec}^{-1}\end{array}$ & $\begin{array}{c}\beta_{\mathrm{c}} \\
\mathrm{mV} \cdot \mathrm{dec}^{-1}\end{array}$ & $\begin{array}{c}\mathrm{Rp} \\
\Omega \cdot \mathrm{cm}^{2}\end{array}$ & $\begin{array}{c}\mathrm{WL} \\
\mathrm{Mg} \cdot \mathrm{m}^{-2} \mathrm{~d}^{-1}\end{array}$ & $\begin{array}{c}\mathrm{PL} \\
\mathrm{mm} \cdot \mathrm{y}^{-1}\end{array}$ & $\theta$ & $\mathrm{PE} \%$ \\
\hline \multirow{4}{*}{$\begin{array}{l}\text { Uncoated } \\
\text { SS }\end{array}$} & 20 & -179.2 & 27.00 & 113.8 & 101.6 & 801.5 & 6.75 & 0.3024 & & \\
\hline & 30 & -194.7 & 31.23 & 125.7 & 106.5 & 581.1 & 7.80 & 0.3497 & & \\
\hline & 40 & -202.2 & 44.34 & 141.3 & 102.3 & 446.5 & 11.08 & 0.4966 & & \\
\hline & 50 & -215.6 & 59.23 & 137.3 & 109.5 & 257.8 & 14.80 & 0.6633 & & \\
\hline \multirow{4}{*}{$\begin{array}{l}\text { Reduced } \\
\text { GO } \\
\text { coated SS }\end{array}$} & 20 & -65.4 & 1.22 & 116 & 192.1 & 3881.7 & 0.30 & 0.0136 & 0.954 & 95.4 \\
\hline & 30 & -172.2 & 6.51 & 111.7 & 121.5 & 1262.3 & 1.62 & 0.0729 & 0.791 & 79.1 \\
\hline & 40 & -171.6 & 13.46 & 76.5 & 80.1 & 1719.9 & 3.36 & 0.1507 & 0.696 & 69.6 \\
\hline & 50 & -167.8 & 16.04 & 98.5 & 179 & 501.8 & 4.01 & 0.1796 & 0.729 & 72.9 \\
\hline \multirow{4}{*}{$\begin{array}{l}\text { Uncoated } \\
\mathrm{Cu}\end{array}$} & 20 & -206.6 & 25.61 & 251 & 80.3 & 1031.4 & 7.27 & 0.2970 & & \\
\hline & 30 & -204.9 & 30.95 & 338.7 & 90.7 & 1003.7 & 8.78 & 0.3590 & & \\
\hline & 40 & -211.3 & 47.41 & 322.6 & 90.8 & 648.9 & 13.46 & 0.5499 & & \\
\hline & 50 & -222.3 & 56.4 & 278.7 & 88.8 & 518.4 & 16.01 & 0.6542 & & \\
\hline \multirow{4}{*}{$\begin{array}{l}\text { Reduced } \\
\text { GO } \\
\text { coated } \\
\mathrm{Cu}\end{array}$} & 20 & -145.1 & 6.01 & 72.3 & 58.3 & 2331.8 & 1.70 & 0.0697 & 0.765 & 76.5 \\
\hline & 30 & -140.8 & 10.66 & 53.5 & 47 & 1019.1 & 3.02 & 0.1236 & 0.655 & 65.5 \\
\hline & 40 & -155.3 & 15.95 & 59.2 & 58.5 & 801.0 & 4.52 & 0.1850 & 0.663 & 66.3 \\
\hline & 50 & -173.1 & 18.76 & 59.2 & 59.4 & 686.2 & 5.32 & 0.2176 & 0.667 & 66.7 \\
\hline \multirow{4}{*}{$\begin{array}{l}\text { Uncoated } \\
\mathrm{Al}\end{array}$} & 20 & -635.7 & 239.38 & 378.7 & 105.7 & 149.8 & 67.98 & 2.7768 & & \\
\hline & 30 & -713.5 & 267.93 & 318.8 & 79.2 & 102.8 & 76.09 & 3.1079 & & \\
\hline & 40 & -676.5 & 317.33 & 424.4 & 103.7 & 114.0 & 90.12 & 3.6810 & & \\
\hline & 50 & -693.2 & 375.11 & 416.6 & 90.8 & 86.2 & 106.53 & 4.3512 & & \\
\hline \multirow{4}{*}{$\begin{array}{l}\text { Reduced } \\
\text { GO } \\
\text { coated Al }\end{array}$} & 20 & -647.9 & 88.22 & 75.0 & 72.1 & 180.9 & 25.05 & 1.0233 & 0.631 & 63.1 \\
\hline & 30 & -670.1 & 94.54 & 81.0 & 73.4 & 176.8 & 26.84 & 1.0966 & 0.647 & 64.7 \\
\hline & 40 & -644.2 & 115.01 & 101.9 & 74 & 161.8 & 32.66 & 1.3341 & 0.637 & 63.7 \\
\hline & 50 & -735.0 & 118.7 & 98.4 & 95.5 & 177.2 & 33.71 & 1.3769 & 0.683 & 68.3 \\
\hline
\end{tabular}

TABLE 2: The calculated thermodynamic functions, $E_{\mathrm{a}}, \Delta H^{*}, \Delta S^{*}$, and $\Delta G^{*}$, for the corrosion process of the uncoated and reduced GO coated $\mathrm{SS}, \mathrm{Cu}$, and $\mathrm{Al}$ in seawater.

\begin{tabular}{|c|c|c|c|c|c|c|c|}
\hline \multirow{2}{*}{$\begin{array}{l}\text { System in } 3.5 \% \\
\text { NaCL }\end{array}$} & \multirow{2}{*}{$E_{\mathrm{a}} \mathrm{kJ} \cdot \mathrm{mol}^{-1}$} & \multirow{2}{*}{$\begin{array}{c}\Delta H^{*} \\
\mathrm{~kJ} \cdot \mathrm{mol}^{-1}\end{array}$} & \multirow{2}{*}{$\begin{array}{c}\Delta S^{*} \\
\mathrm{~J} \cdot \mathrm{mol}^{-1}\end{array}$} & \multicolumn{4}{|c|}{$\Delta G^{*}\left(\mathrm{~kJ} \cdot \mathrm{mol}^{-1}\right)$} \\
\hline & & & & 20 & 30 & 40 & 50 \\
\hline Uncoated SS & 21.217 & -18.66 & -154.16 & 26.500 & 28.002 & 29.604 & 31.146 \\
\hline G-coated SS & 67.264 & -64.708 & -19.35 & 59.03 & 58.844 & 58.65 & 58.45 \\
\hline Uncoated $\mathrm{Cu}$ & 30.236 & -19.430 & -151.75 & 25.032 & 26.550 & 28.067 & 29.585 \\
\hline G-coated Cu & 19.405 & -27.679 & -134.71 & 11.791 & 13.138 & 14.485 & 15.832 \\
\hline Uncoated Al & 11.901 & -9.343 & -167.52 & 58.426 & 60.101 & 61.776 & 63.451 \\
\hline G-coated Al & 8.561 & -6.004 & -187.12 & 60.830 & 62.701 & 64.572 & 66.443 \\
\hline
\end{tabular}

uncoated ones which support the good protection efficiencies (70-95\%) for SS, while the decrease in apparent activation energy for the graphene coated $\mathrm{Cu}$ and $\mathrm{Al}$ leads to less protection efficiencies, around $65 \%$ in this case; the number of corrosion sites can be represented by preexponential factor $A$ in the Arrhenius equation:

$$
R=A e^{-E_{\mathrm{a}} / \mathrm{RT}}
$$

$A$ is a term which includes factors like the frequency of collisions and their orientation. It varies slightly with temperature but highly with the type of surface and is responsible for the corrosion protection abilities rather than $E_{\mathrm{a}}$ as in the case of $\mathrm{Al}$ and $\mathrm{Cu}[26]$.

On the other hand, the corrosion potentials or the open circuit potentials values of the reduced graphene coated specimens went to less negative values as compared to the uncoated ones.

The polarization resistances of the uncoated samples of SS316 and copper were always less than the coated samples, which can be attributed to the existence of some nonconductive graphene oxide [27], except for Al which shows the 


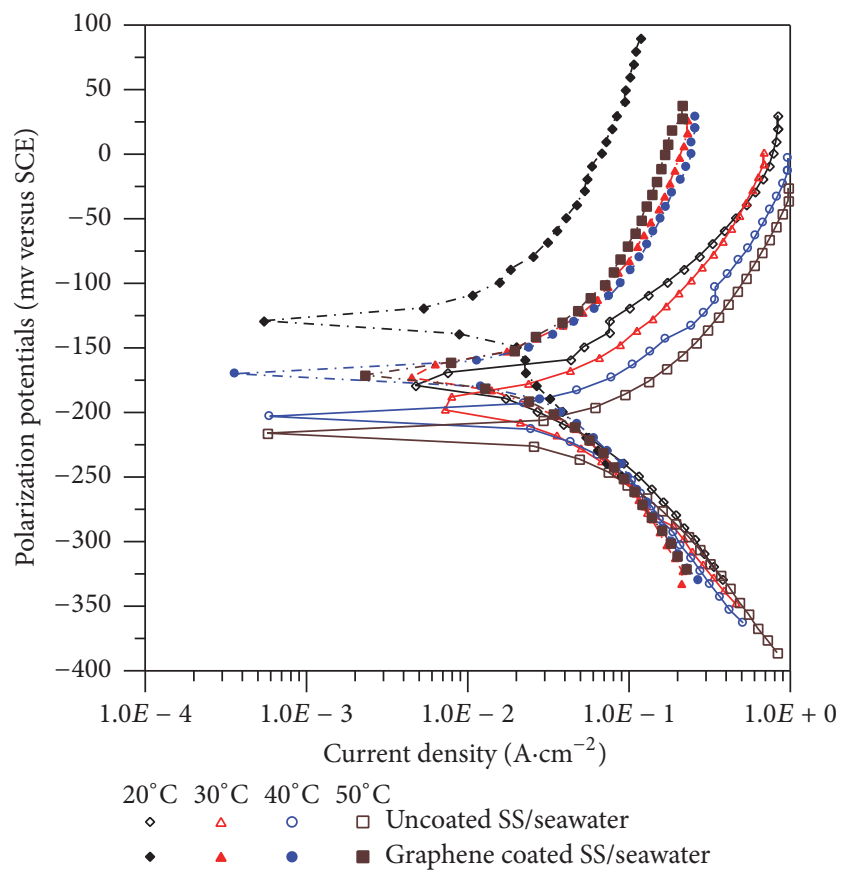

FIGURE 10: Tafel plots of SS316 specimens in seawater system without and with reduced GO coating at different temperature.

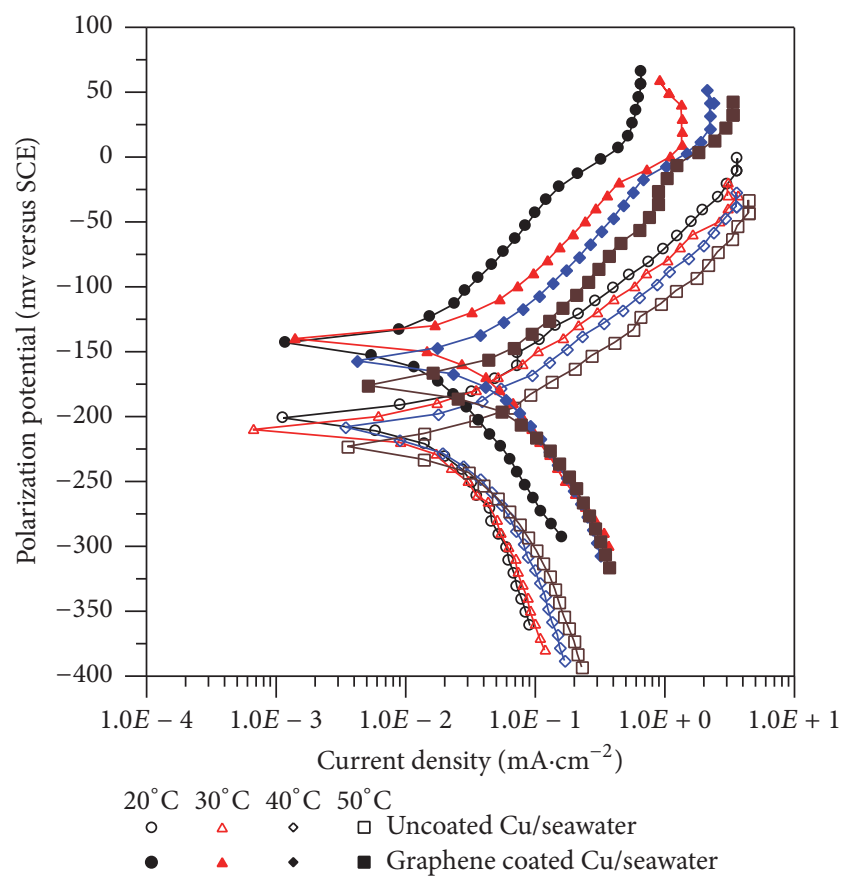

FIGURE 11: Tafel plots of copper specimens in seawater system without and with reduced GO coating at different temperature.

reverse of this behavior; the reason for such manner is the ability of $\mathrm{Al}$ to liberate hydrogen gas in the aqueous solution [28].

The result suggests that corrosion inhibition by the reduced graphene layer is brought about by increasing its activation energy. There is an increase in $E_{\mathrm{a}}$ as a nature of the surface of the SS changed making a barrier for mass and

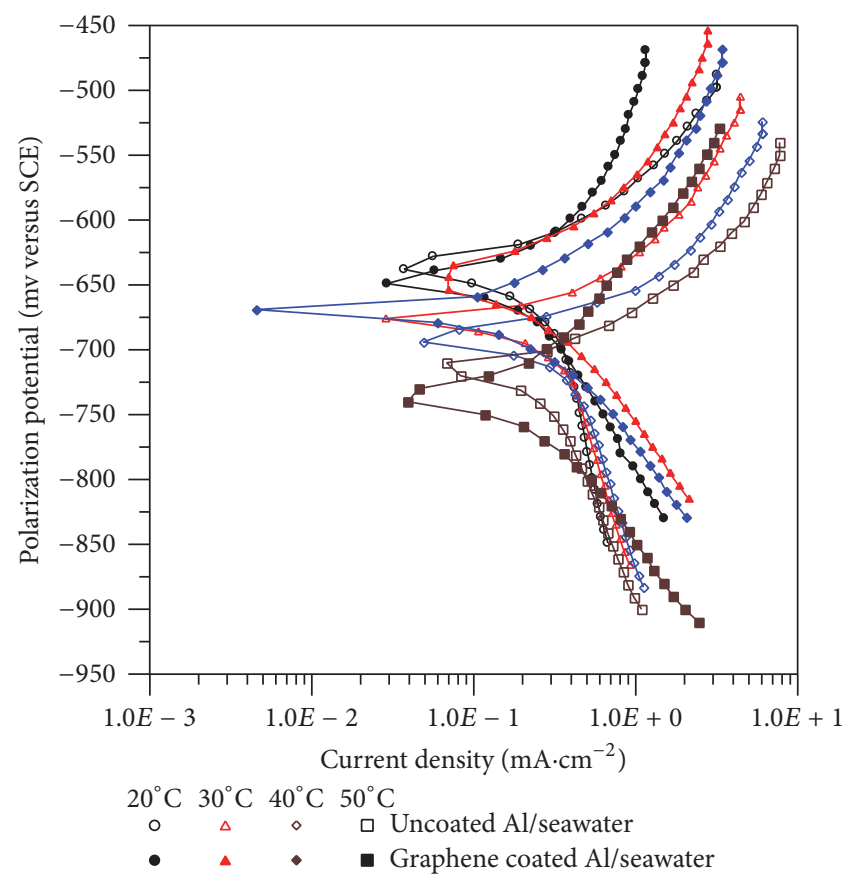

Figure 12: Tafel plots of aluminum specimens in seawater system without and with reduced GO coating at different temperature.

charge transfer. The range of $E_{\mathrm{a}}$ values (from $21 \mathrm{KJ} / \mathrm{mol}$ to $67 \mathrm{KJ} / \mathrm{mol}$ ) is lower than the threshold value of $80 \mathrm{KJ} / \mathrm{mol}$ required for chemisorption. This means that adsorption is physical adsorption [29]. Hence, the slightly higher energy of activation values suggests strong physisorption.

Generally, the values of $\Delta H^{*}$ lower than $40 \mathrm{KJ} / \mathrm{mol}$ which attributed the physical adsorption and the value $100 \mathrm{KJ} / \mathrm{mol}$ indicate chemical adsorption From Table 2; it was found that the negative sign and values $(6.004 \mathrm{KJ} / \mathrm{mol} 64.708 \mathrm{KJ} / \mathrm{mol})$ of activation of enthalpy $\left(\Delta H^{*}\right)$ reflect the exothermic corrosion process [30]. The increase in $\Delta H^{*}$ for the graphene coated specimens reveals that corrosion rate is mainly controlled by kinetic parameters of activation [31]. The values of $\Delta S^{*}$ for the uncoated and graphene coated are negative. This implies that the activation complex is the rate determining step representing association rather than dissociation, indicating that a decrease in disorder takes place going from reactants to the activated complex [32].

\section{Conclusions}

Good adhered continuous layers of reduced graphene oxide were deposited electrochemically from solution of graphene oxide synthesized via Hammers procedure, on surfaces of stainless steel 316, copper, and aluminum; these layers exhibited good corrosion inhibition properties against artificial seawater in the temperature range of 20 to $50^{\circ} \mathrm{C}$.

\section{Conflicts of Interest}

The authors declare that they have no conflicts of interest. 


\section{Acknowledgments}

The authors thank Dr. Khalid Ajme, the Director of Nanotechnology Center, University of Technology, for SEM and $\mathrm{XRD}$ analysis.

\section{References}

[1] M. S. Dresselhaus and P. T. Araujo, "Perspectives on the 2010 nobel prize in physics for graphene," ACS Nano, vol. 4, no. 11, pp. 6297-6302, 2010.

[2] M. F. Montemor, "Functional and smart coatings for corrosion protection: a review of recent advances," Surface and Coatings Technology, vol. 258, pp. 17-37, 2014.

[3] Y. W. Chen-Yang, H. C. Yang, G. J. Li, and Y. K. Li, “Thermal and anticorrosive properties of polyurethane/clay nanocomposites," Journal of Polymer Research, vol. 11, no. 4, pp. 275-283, 2005.

[4] C. Mattevi, H. Kim, and M. Chhowalla, "A review of chemical vapour deposition of graphene on copper," Journal of Materials Chemistry, vol. 21, no. 10, pp. 3324-3334, 2011.

[5] Z. Sun, D. K. James, and J. M. Tour, "Graphene chemistry: synthesis and manipulation," The Journal of Physical Chemistry Letters, vol. 2, no. 19, pp. 2425-2432, 2011.

[6] M. Yi and Z. Shen, "A review on mechanical exfoliation for the scalable production of graphene," Journal of Materials Chemistry A, vol. 3, no. 22, pp. 11700-11715, 2015.

[7] H. Hibino, H. Kageshima, and M. Nagase, "Epitaxial few-layer graphene: towards single crystal growth," Journal of Physics D: Applied Physics, vol. 43, no. 37, Article ID 374005, 2010.

[8] D. S. Lee, C. Riedl, B. Krauss, K. V. Klitzing, U. Starke, and J. $\mathrm{H}$. Smet, "Raman spectra of epitaxial graphene on $\mathrm{SiC}$ and of epitaxial graphene transferred to $\mathrm{SiO}_{2}$," Nano Letters, vol. 8, no. 12, pp. 4320-4325, 2008.

[9] S. Stankovich, D. A. Dikin, R. D. Piner et al., "Synthesis of graphene-based nanosheets via chemical reduction of exfoliated graphite oxide," Carbon, vol. 45, no. 7, pp. 1558-1565, 2007.

[10] W. K. Chee, H. N. Lim, N. M. Huang, and I. Harrison, "Nanocomposites of graphene/polymers: a review," RSC Advances, vol. 5, no. 83, pp. 68014-68051, 2015.

[11] Y. S. Lim, Y. P. Tan, H. N. Lim et al., "Polypyrrole/graphene composite films synthesized via potentiostatic deposition," Journal of Applied Polymer Science, vol. 128, no. 1, pp. 224-229, 2013.

[12] C.-H. Chang, T.-C. Huang, C.-W. Peng et al., "Novel anticorrosion coatings prepared from polyaniline/graphene composites," Carbon, vol. 50, no. 14, pp. 5044-5051, 2012.

[13] B. P. Singh, S. Nayak, K. K. Nanda, B. K. Jena, S. Bhattacharjee, and L. Besra, "The production of a corrosion resistant graphene reinforced composite coating on copper by electrophoretic deposition," Carbon, vol. 61, pp. 47-56, 2013.

[14] B. P. Singh, B. K. Jena, S. Bhattacharjee, and L. Besra, "Development of oxidation and corrosion resistance hydrophobic graphene oxide-polymer composite coating on copper," Surface and Coatings Technology, vol. 232, pp. 475-481, 2013.

[15] W. S. Hummers Jr. and R. E. Offeman, "Preparation of graphitic oxide," Journal of the American Chemical Society, vol. 80, no. 6, p. 1339, 1958.

[16] D. R. Dreyer, S. Park, C. W. Bielawski, and R. S. Ruoff, “The chemistry of graphene oxide," Chemical Society Reviews, vol. 39, no. 1, pp. 228-240, 2010.

[17] L. M. Malard, M. A. Pimenta, G. Dresselhaus, and M. S. Dresselhaus, "Raman spectroscopy in graphene," Physics Reports, vol. 473, no. 5-6, pp. 51-87, 2009.
[18] S. Park, J. An, J. R. Potts, A. Velamakanni, S. Murali, and R. S. Ruoff, "Hydrazine-reduction of graphite- and graphene oxide," Carbon, vol. 49, no. 9, pp. 3019-3023, 2011.

[19] D. A. Dikin, S. Stankovich, E. J. Zimney et al., "Preparation and characterization of graphene oxide paper," Nature, vol. 448, no. 7152, pp. 457-460, 2007.

[20] K. N. Kudin, B. Ozbas, H. C. Schniepp, R. K. Prud'homme, I. A. Aksay, and R. Car, "Raman spectra of graphite oxide and functionalized graphene sheets," Nano Letters, vol. 8, no. 1, pp. 36-41, 2008.

[21] A. C. Ferrari, "Raman spectroscopy of graphene and graphite: disorder, electron-phonon coupling, doping and nonadiabatic effects," Solid State Communications, vol. 143, no. 1-2, pp. 47-57, 2007.

[22] F. Mansfeld, "Tafel slopes and corrosion rates from polarization resistance measurements," Corrosion, vol. 29, no. 10, pp. 397402, 1973.

[23] S. G. Millard, D. Law, J. H. Bungey, and J. Cairns, "Environmental influences on linear polarisation corrosion rate measurement in reinforced concrete," NDT and E International, vol. 34, no. 6, pp. 409-417, 2001.

[24] A. A. Khadom, A. S. Yaro, A. S. AlTaie, and A. A. Kadum, "Electrochemical, activations and adsorption studies for the corrosion inhibition of low carbon steel in acidic media," Portugaliae Electrochimica Acta, vol. 27, no. 6, pp. 699-712, 2009.

[25] E. A. Noor, "Temperature effects on the corrosion inhibition of mild steel in acidic solutions by aqueous extract of fenugreek leaves," International Journal of Electrochemical Science, vol. 2, no. 12, pp. 996-1017, 2007.

[26] A. Y. El-Etre, "Inhibition of aluminum corrosion using Opuntia extract," Corrosion Science, vol. 45, no. 11, pp. 2485-2495, 2003.

[27] S. Pei and H.-M. Cheng, "The reduction of graphene oxide," Carbon, vol. 50, no. 9, pp. 3210-3228, 2012.

[28] A. Y. El-Etre, "Inhibition of acid corrosion of aluminum using vanillin," Corrosion Science, vol. 43, no. 6, pp. 1031-1039, 2001.

[29] A. W. Adamson, Physical Chemistry of Surfaces, John Wiley \& Sons, 6th edition, 2006.

[30] L. Herrag, B. Hammouti, S. Elkadiri et al., "Adsorption properties and inhibition of mild steel corrosion in hydrochloric solution by some newly synthesized diamine derivatives: experimental and theoretical investigations," Corrosion Science, vol. 52, no. 9, pp. 3042-3051, 2010.

[31] A. M. Abdel-Gaber, E. Khamis, H. Abo-ElDahab, and S. Adeel, "Inhibition of aluminium corrosion in alkaline solutions using natural compound," Materials Chemistry and Physics, vol. 109, no. 2-3, pp. 297-305, 2008.

[32] S. A. M. Refaey, F. Taha, and A. M. A. El-Malak, "Inhibition of stainless steel pitting corrosion in acidic medium by 2mercaptobenzoxazole," Applied Surface Science, vol. 236, no. 1, pp. 175-185, 2004. 

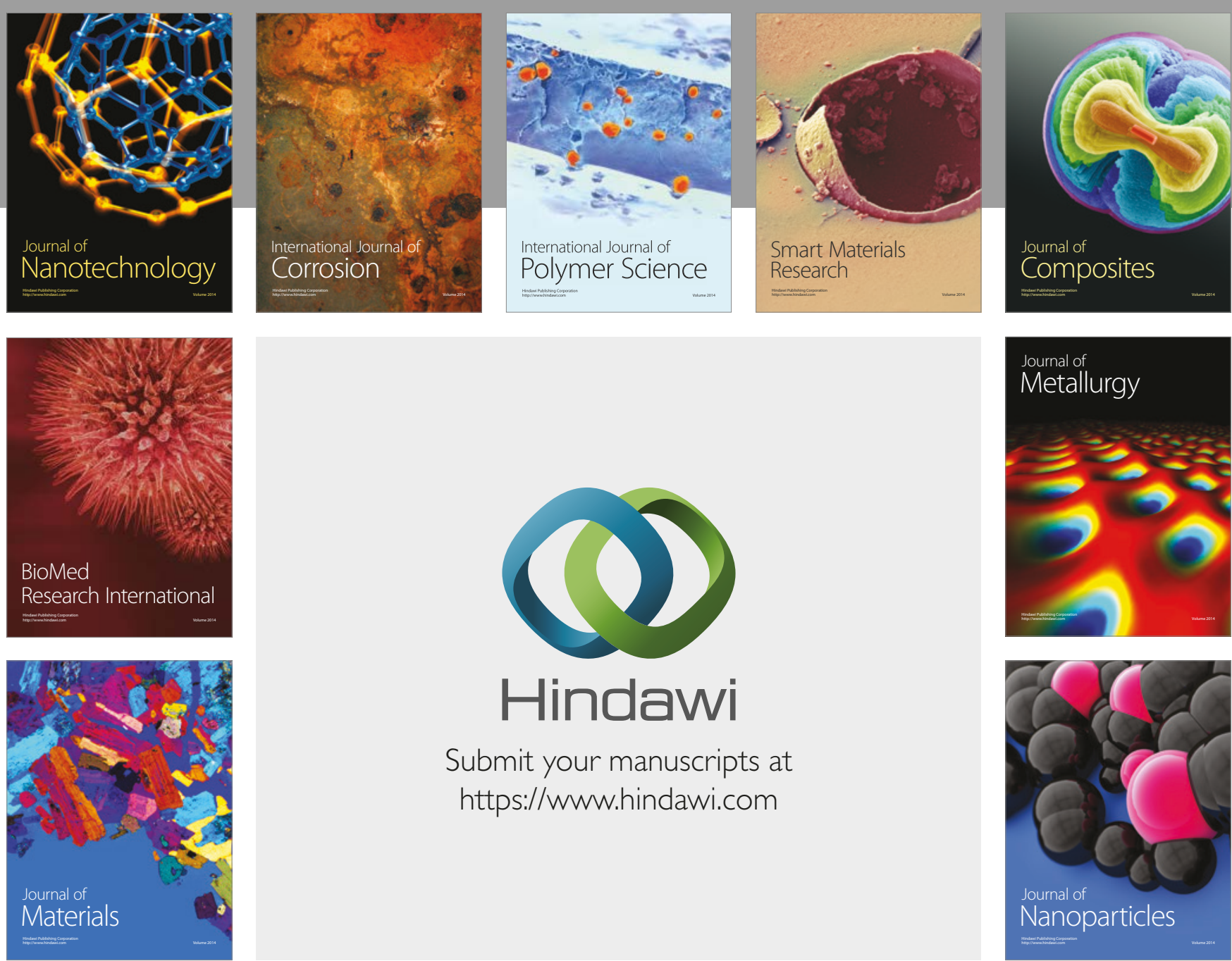

\section{Hindawi}

Submit your manuscripts at

https://www.hindawi.com
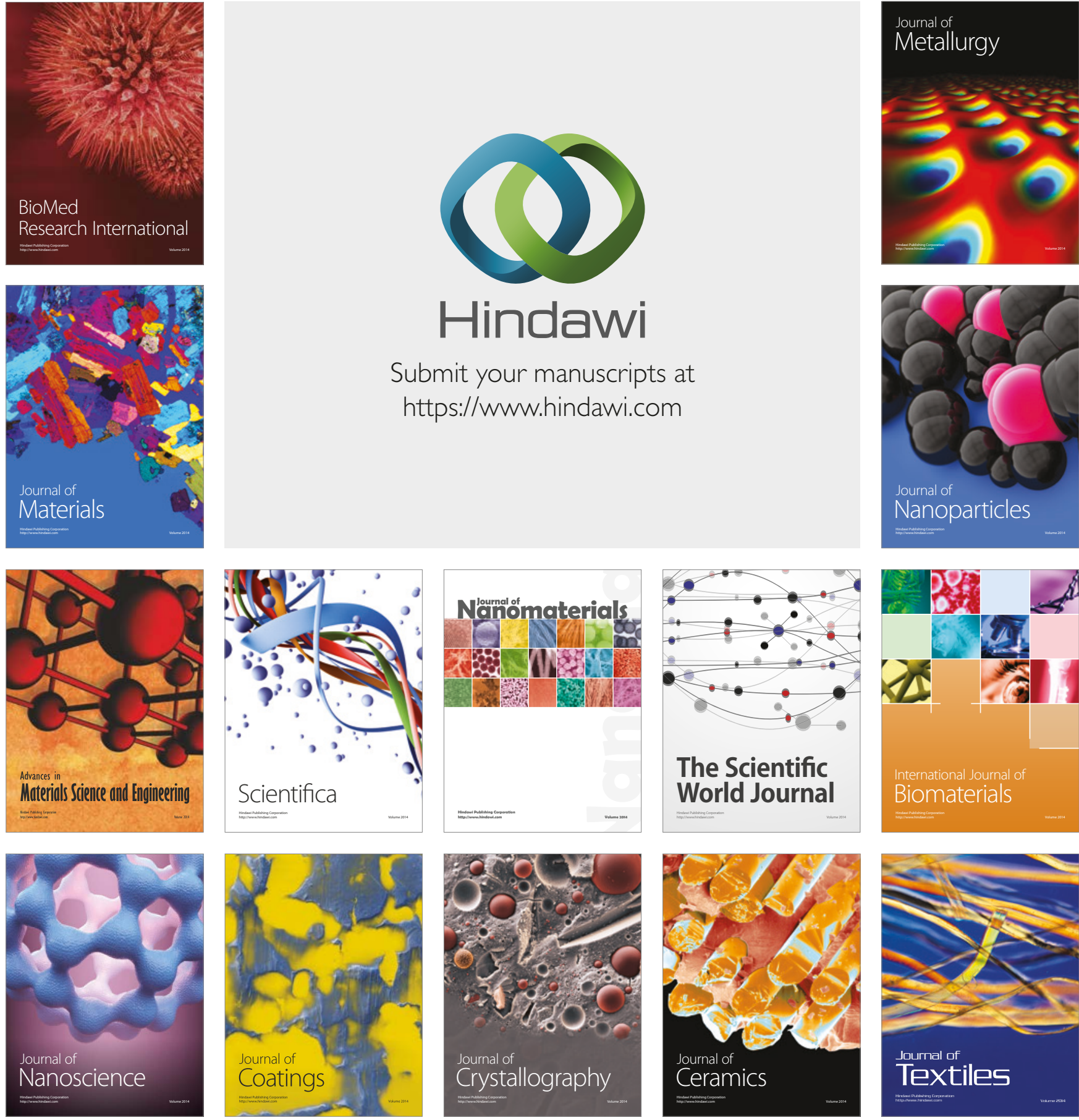

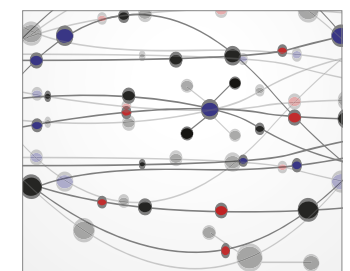

The Scientific World Journal
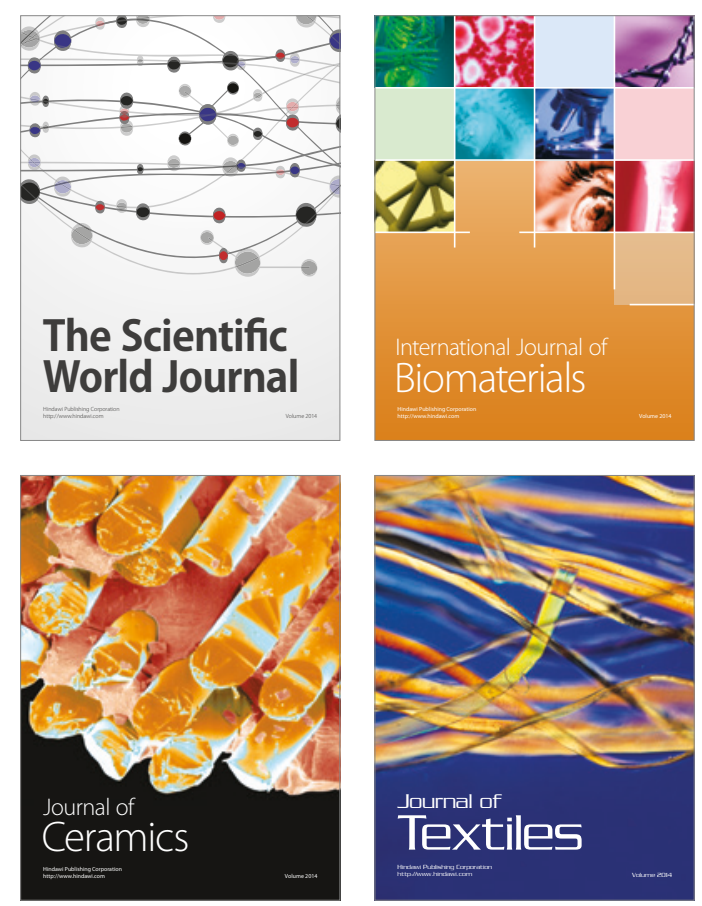